Physical signs were observed at once which suggested a blood disorder. Respiration was established without difficulty and the lungs appeared to expand normally but mild cyanosis persisted. Clinically and radiologically there was no evidence of congenital heart disease, but the liver was considerably enlarged. No glands were felt and the spleen was impalpable at the initial examination, but in view of the known association of Down's syndrome with congenital leukaemia a blood count was obtained about eight hours after birth. Arrangements were also made for chromosome studies to be undertaken, but as the infant was born during the August Bank Holiday investigations were necessarily limited. The blood count showed $\mathrm{Hb} 18 \mathrm{~g} / 100$ ml, haemotocrit 54, M.C.H.C. 33, W.B.C.s $320,000 / \mathrm{mm}^{3}$, (neutrophils $10 \%$, lymphocytes $8 \%$, monocytes $4 \%$, metamyelocytes $10 \%$, myelocytes $18 \%$, promyelocytes $10 \%$, myeloblasts $40 \%$ ). No platelet count was done. There was no evidence of sepsis, the mother's W.R. was negative, blood group of mother and infant was $\mathrm{O} \mathbf{R h}+$, and the indirect Coombs test was negative, so leukaemoid reaction to sepsis, congenital syphilis, or erythroblastosis appeared to be excluded.

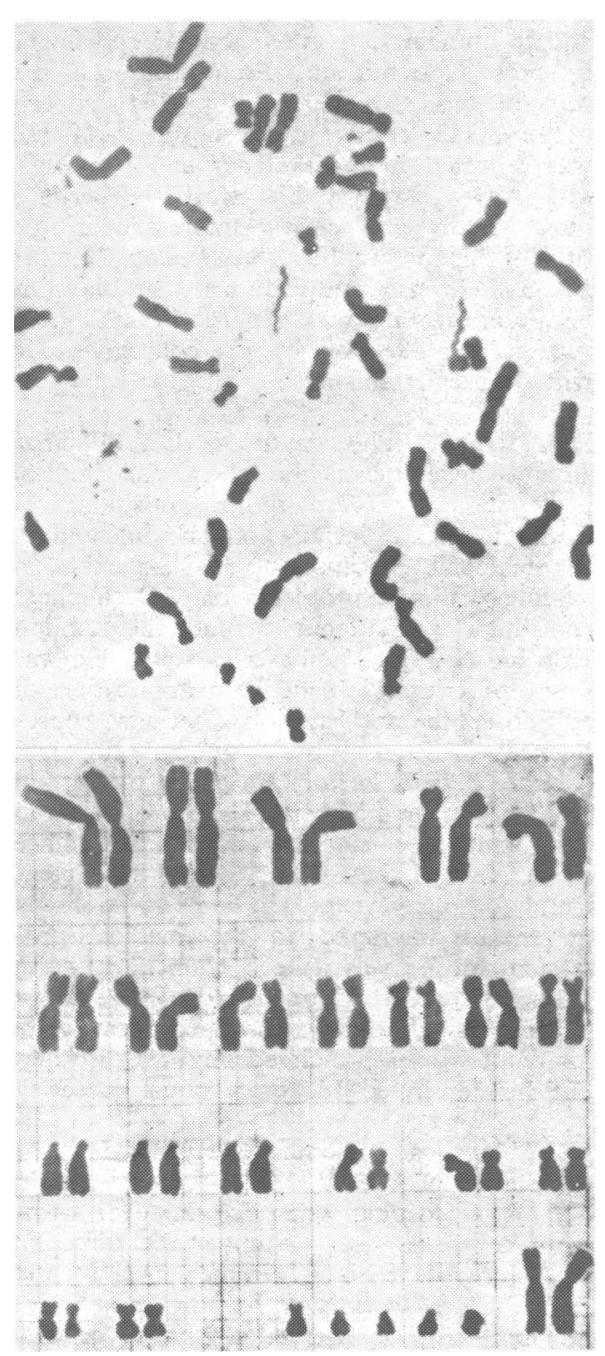

FIG.-Cell from fibroblast culture.

The baby became dyspnoeic and more cyanosed, the liver increased in size, and the spleen became palpable before she died 48 hours after birth. The mode of death was very similar to that described by Pierce $^{1}$ who found that the majority of infants exhibiting signs of leukaemia at birth died within a few days, often from respiratory insufficiency caused by atelectasis or pulmonary infiltration. The transient leukaemia-like blood picture sometimes seen in mongols after birth need not be considered in this case since the condition proved fatal and was clearly of intra-uterine origin and long standing.

Postmortem examination showed the lungs to be expanded, with congestive changes and patchy atelectasis. There was no pneumonia. The liver was grossly enlarged, parenchyma being obscured by extensive extramedullary haemopoiesis, predominantly leukoblastic. Kidneys also showed foci of haemopoietic cells in the cortex. The spleen pulp was grossly abnormal with extensive leukoblastic activity and absence of Malpighian bodies Bone marrow was cellular with normal distribution of haemopoietic tissue, but an excess of megakaryocytes and leukopoietic elements.

Chromosome studies (Fig.) confirmed the diagnosis of mongolism and the blood picture was regarded as that of acute myeloblastic leukaemia.-I am, etc.,

Bushey Heath,

MARgaret BABER

Herts

1 Pierce, M., Fournal of Paediatrics, 1959, 54, 691. Wegelius, R., Väänänen, I., and Koskela, S.-L.
Acta Paediatrica Scandinavica, 1967, 56, 301.

\section{Wegener's Granulomatosis}

SIR,-It is surprising that your leading article on "Wegener's Granulomatosis" (21 August, p. 446) fails to mention the very striking results obtained in this condition with the use of large doses of cyclophosphamide. 1 Each of the patients treated had extensive pulmonary and central nervous system involvement and lesser degrees of renal involvement and sinusitis. Corticosteroid therapy had proved without effect in all cases.

There was rapid improvement in signs and symptoms in four patients after cyclophosphamide had been started. Almost all evidence of disease disappeared. In one patien it was possible to discontinue the drug for 20 months and in another for 12 months. The other two patients were asymptomatic for three and a half years on continued low doses of cyclophosphamide.-I am, etc.,

\section{R. M. SYKES}

Sefton General Hospital,

Liverpool 15

1 Novack, S. N., and Pearson, C. M., New England fournal of Medicine, 1971, 284, 938.

\section{Halothane Hepatitis}

SIR,-Mr. J. D. Langdon ${ }^{1}$ quotes Professor W. W. Mushin and colleagues (3 July, p. 18) as an authority for his statement that "there is no longer any doubt that in a small number of cases halothane administration does precipitate hepatitis." It is unfortunate that the summary which appears in bold print at the beginning of the paper by Professor Mushin and his colleagues is so misleading and open to misinterpretation, because in a subsequent letter Professor Mushin and Dr. M. Rosen state quite clearly that they did not intend to supply an answer as to whether halothane is the causal element in "posthalothane jaundice." (14 August, p. 431).

The study by Professor Mushin and his colleagues established the high incidence of postoperative jaundice following two operations in less than one month. Since halothane is now used in $90 \%$ of anaesthetic procedures in this country it is therefore inevitable that halothane will be present as a co-incidental factor in the great majority of cases when postoperative jaundice occurs. As yet, no data have been provided which implicate halothane further than that (24 July, p. 245).-We are, etc.,

\section{B. R. SIMPSON}

L. STRUNIN

Anaesthetics Unit,

London Hospital,

1 Langdon, J. D., British Dental fournal, 1971, $131,94$.

\section{Non-specific Backache}

SIR,-The formation of a Back Pain Club such as your leading article describes (2 October, p. 4) is a welcome event. Backache spoils so many people's lives, and provides one of the major causes of industrial invalidism today. Its importance was emphasized by a survey ("The Sair Back") in Glasgow of over six million episodes off work in 1966.' This revealed that middleaged employees with back trouble stayed away from work for an average of five months. Since there must be many people in that city who spend a week or two in bed and then return to work, this figure implies that a sizeable proportion absent themselves for a year. Here is a challenge indeed, involving millions of public money.

Naturally diagnosis leading to logical treatment and the detection of symptoms devoid of organic basis are both essential Future progress must rely on research, but surely the first step is to disseminate to every hospital the large body of clinical knowledge that has already been accumulated, and to make available within the N.H.S. for the first time treatments well known to succeed. This plan could be implemented immediately.

Little is to be gained by lumping difficult cases together under the vague term "nonspecific backache." There is a simple way out that I have employed daily since 1937 diagnostic epidural local anaesthesia. This injection has proved a reliable criterion for differentiating disc backache from non-disc backache. If a patient with a lesion of a lumbar moving part finds that his movements become painless after the external aspect of the dura mater and of the nerve roots has been rendered insensitive, a disc lesion must be responsible. The fluid injected (procaine 1:200) does not enter a joint, nor cause a detectable nerve palsy, nor reach the anterior aspect of the posterior longitudinal ligament against which a protruded disc engages. Where the fluid runs is clearly shown by the contrast radiographs (Plates 44-48) reproduced in succeeding editions of my book. ${ }^{2}$

I suggest that the Club need not start from scratch, but can base its further investigations on facts already ascertained and knowledge already in existence.-I am, etc.,

London $\mathbb{W} .1$

JAMES CyRIAX

1 Symposium on Clinical Problems of Practice, Fournal of the Royal College of Practitioners, $1967,13,60$

2 Cyriax, J., Textbook of Orthopaedic Medicine, 5 th edn. London, Ballière, Tindall, 1970 . 